\title{
Effect of Precursor Solvents on the Optical Properties of Copper Oxide Thin Films Deposited Using Spray Pyrolysis for Optoelectronic Applications
}

\author{
Adeniyi Yisau Fasasi ${ }^{1,4}$, Edward Osagie ${ }^{1,2}$, David Pelemo ${ }^{1}$, Eusebius Obiajunwa ${ }^{1}$, \\ Emmanuel Ajenifuja ${ }^{1,5,}$, John Ajao ${ }^{1}$, Gabriel Osinkolu ${ }^{1}$, Wasiu Oladotun Makinde ${ }^{1}$, \\ Abiodun Eyitayo Adeoye ${ }^{3}$ \\ ${ }^{1}$ Centre for Energy Research \& Development, Obafemi Awolowo University, Ile-Ife, Nigeria \\ ${ }^{2}$ Department of Physics and Engineering Physics, Obafemi Awolowo University, Ile-Ife, Nigeria \\ ${ }^{3}$ Department of Physical Sciences, Technical University, Ibadan, Nigeria \\ ${ }^{4}$ Department of Physics and Applied Mathematics, Osun State University, Osogbo, Nigeria \\ ${ }^{5}$ Department of Chemical, Metallurgical and Materials Engineering, Tshwane University of Technology, Pretoria, South Africa
}

Email address:

eajenifuja@gmail.com (E.Ajenifuja), ajenifujae@tut.ac.za (E. Ajenifuja)

${ }^{*}$ Corresponding author

\section{To cite this article:}

Adeniyi Yisau Fasasi, Edward Osagie, David Pelemo, Eusebius Obiajunwa, Emmanuel Ajenifuja, John Ajao, Gabriel Osinkolu, Wasiu Oladotun Makinde, Abiodun Eyitayo Adeoye. Effect of Precursor Solvents on the Optical Properties of Copper Oxide Thin Films Deposited Using Spray Pyrolysis for Optoelectronic Applications. American Journal of Materials Synthesis and Processing.

Vol. 3, No. 2, 2018, pp. 12-22. doi: 10.11648/j.ajmsp.20180302.12

Received: June 12, 2018; Accepted: June 26, 2018; Published: July 25, 2018

\begin{abstract}
Copper oxide thin films were deposited on Pyrex glass substrates by spray pyrolysis using ethanol and distilled water (DW) respectively as solvents. Rutherford backscattering spectroscopy results indicated that films from aqueous are thicker than those of alcoholic solutions. Rutherford backscattering spectroscopic compositional results showed the films to be mainly $\mathrm{CuO}$. Optical transmittance measurement of the films was analyzed to obtain the band gap, Urbach energy, optical conductivity, refractive index and the extinction coefficient which were found to be dependent on the solvent used and strongly influenced by the photon energy. The use of Tauc's equation for calculating the bandgap indicated possible direct and indirect optical transitions. The refractive index of the films which showed normal dispersion behavior were also analyzed using single oscillator model to determine the dispersion parameters such as the dispersion energy, average oscillator strength and wavelength, zero and high frequency dielectric constant, zero frequency refractive index, optical charge carrier density, mobility and resistivity. All the determined values are higher for ethanol than aqueous samples.
\end{abstract}

Keywords: Copper Oxide, Bandgap, Refractive Index Dispersion, Dielectric Constants, Carrier Density

\section{Introduction}

Copper oxides as semiconductors have been studied for more than three decades because of the abundance of the constituent elements and due to their unique properties leading to diverse applications. The $\mathrm{Cu}-\mathrm{O}$ system forms two well-known oxides; cupric oxide $(\mathrm{CuO})$ which is black in colour and cuprous oxide $\left(\mathrm{Cu}_{2} \mathrm{O}\right)$ which is red or slightly yellow. Both $\mathrm{CuO}$ and $\mathrm{Cu}_{2} \mathrm{O}$ are generally believed to be $\mathrm{p}$ type semiconductors having band gap energies in the visible and near infrared regions of 1.21 to $1.51 \mathrm{eV}$ and 2.10 to 2.60 $\mathrm{eV}$ respectively [1]. Conduction mechanism arises from holes in the valence band due to doping and annealing. $\mathrm{CuO}$ has been widely investigated for various potential applications such as lithium ion electrodes [2], sensors [3], high critical temperature superconductors, field emission emitter [4], photocatalyst [5], resistive switching [6] and can also be employed as a solar absorber because of its high absorption coefficient and a low thermal emittance. It has also been employed as a barrier layer in dye sensitized solar cells [7] as 
well as improving the grain size of spin-coated $\mathrm{ZnO}-\mathrm{CuO}$ composite [8]. $\mathrm{Cu}_{2} \mathrm{O}$ on the other hand has not been widely used in solar cells because of its low energy conversion efficiency because light generated from micron-sized grains are not effectively transferred to the surface and are lost due to recombination [9] but because of its band gap, it could also be used as anode materials in thin film lithium batteries due to its high optical absorption coefficient in the visible region and good electrical properties. Many authors have demonstrated that $\mathrm{Cu}_{2} \mathrm{O}$ could be $\mathrm{n}$ - or p-type depending on the method of preparation, stoichiometry and the structure of the film [10-13].

Functional thin films such as oxides, sulphides, nitrides and oxynitride are synthesized using different deposition techniques among which are thermal evaporation [14-16], chemical bath methods [17-18], sputtering [19-23], electroplating [24] electrodeposition [25], pulsed laser deposition [26], sol-gel [27-29], successive ionic layer adsorption and reaction (SILAR) [30] and spray pyrolysis [31-36]. Some of these methods have been employed to produce single oxide $\mathrm{Cu}_{x} \mathrm{O}$ thin films and among these methods, spray pyrolysis has been proven to be simple, cheap and fast to scale-up. It can be used to cover large surface area on glass, ceramic and polymeric substrates. Hence, spray pyrolysis has been employed in this study to synthesize $\mathrm{Cu}_{x} \mathrm{O}$ films on glass substrates. Of importance to this study is the work of Mahalingam et al., [37], in which the effect of deposition potential on the physical properties of electrodeposited $\mathrm{CuO}$ thin films. $\mathrm{CuO}$ films exhibited indirect transition, with thickness and band gap increasing as the deposition potential is increased [37]. In the same vein, Dubal et al. [18] investigated the effect of two organic surfactants such as Triton X-100 and polyvinyl alcohol (PVA) on structural, morphological, surface areas and electrochemical properties of $\mathrm{CuO}$ thin films. It was observed that the organic surfactants played important roles in modifying the surface morphology, surface area and pore size distribution leading to improved pseudo-capacitance, increased specific capacitance, high power performance as well as long term cycling stability.

Recent contributions on the synthesis of $\mathrm{Cu}_{x} \mathrm{O}$ films focused mainly on the application as gas sensor, solar cells without fully understanding the stoichiometry and determining the complete optical parameters of the films. This study therefore focused on the effect of precursor solvents on the optical parameters of $\mathrm{Cu}_{x} \mathrm{O}$ films deposited by spray pyrolysis. To achieve this, Rutherford backscattering spectroscopy (RBS) and UV-visible spectrophotometer have been employed to determine the composition, thickness, and optoelectronic parameters of the deposited films.

\section{Materials and Methods}

\subsection{Experimental Procedure}

Two different solvents were employed in this study; ethanol and distilled water. The starting solutions were prepared from analytical grade copper (II) chloride $\left(\mathrm{CuCl}_{2}\right)$ purchased from Sigma Aldrich and was used as purchased without any further purification. All the solutions in ethanol and DI were $0.1 \mathrm{M}$ in concentrations. Aqueous solution of Copper (II) chloride was prepared by dissolving $2.56 \mathrm{~g}$ of the salt in $250 \mathrm{ml}$ of distilled water. Ethanol solution was prepared by dissolving the same weight of $\mathrm{CuCl}_{2}$ in a mixture of $200 \mathrm{ml}$ of ethanol and $50 \mathrm{ml}$ of distilled water. Each solution was thoroughly homogenized using a magnetic stirrer. The glass substrates were cleaned sequentially in dilute hydrochloric acid, alcohol and deionized water and dried in an oven before deposition at a substrate temperature of $320 \pm 5^{\circ} \mathrm{C}$ and nozzle to substrate distance of $23 \mathrm{~cm}$ keeping the number of spray passes at 80 for all the films prepared from the two precursors. Suction-based airbrush and air blast atomizer was employed for the depositions. After deposition, the samples were annealed at $500^{\circ} \mathrm{C}$ in air.

\subsection{Characterizations Details}

The optical properties were studied using Stellanet UVvisible spectrophotometer (Model EP2000) with wavelength covering 200 to $1100 \mathrm{~nm}$. Relevant optical constants of the films were derived from transmission measurements. Rutherford Backscattering Spectroscopy (RBS) experiment was performed using the $1.7 \mathrm{MeV}$ Pelletron Tandem Accelerator at the Centre for Energy Research and Development, Obafemi Awolowo University, Ile-Ife, Nigeria. For this purpose, $2.2 \mathrm{MeV} 4 \mathrm{He}^{2+}$ ion beam was used as the projectile ions. The scattering angle was $165^{\circ}$ and the resolution of the detector was $12 \mathrm{keV}$. All measurements were performed at room temperature with current varying between 20 and $60 \mathrm{nA}$ at a constant charge of $20 \mu \mathrm{C}$. All the spectra were fitted using RBS software (SIMNRA 6.06) for the determination of the composition and the thickness of the films.

\section{Results and Discussion}

\subsection{Effect of Precursor Solvent and Number of Passes}

The effects of ethanol and DW precursor solvents on the transmittance of annealed $\mathrm{Cu}_{x} \mathrm{O}$ samples are shown in Figure 1 (a). It can be observed that between 800 and $900 \mathrm{~nm}$ wavelength, there is no noticeable difference in the transmittance whereas in the visible region below $800 \mathrm{~nm}$, there is a steady decrease in transmittance values for both samples, however, the transmittance of the sample prepared with distilled water is less than that of alcohol for the same number of passes. This shows that the relative dispersion of $\mathrm{Cu}$ ions in the DW prepared precursor solution is lower than that of the ethanol prepared precursor, and that tends to influence the pyrolyzed film transmissions. The decrease in transmittance is an indication of the higher absorbing nature of the DW solvent films. The effect of the number of passes can be observed in Figure 1(b) where as the number of passes is increasing, transmittance is decreasing which is also an 
indication of increase in film thickness. This is not unexpected since more layers are deposited on the substrates as the number of spray-passes increases, leading to higher thickness.
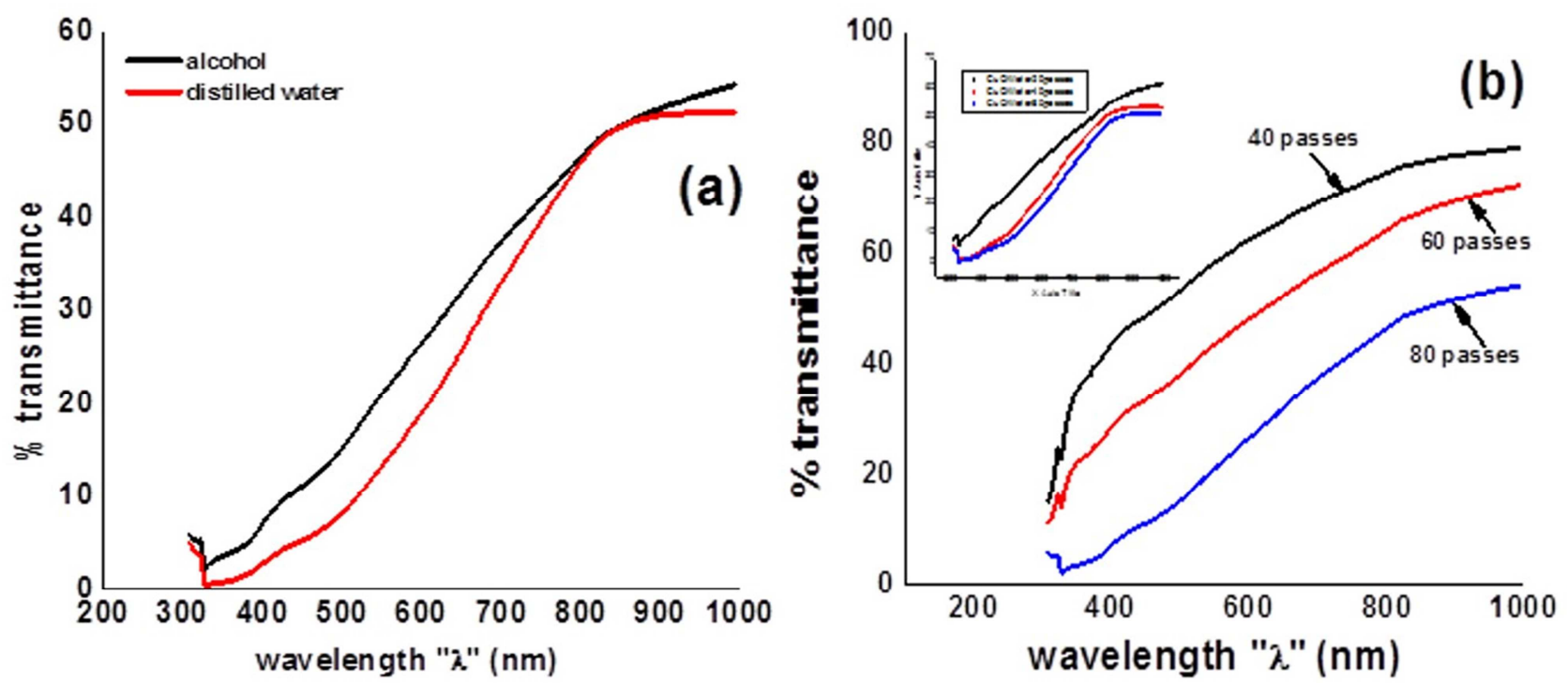

Figure 1. (a) Influence of precursor solvents, and (b) influence of number of passes on transmittance of films for alcohol and the inset shows the influence of DI water as solvent.

\subsection{Stoichiometric Composition and Thickness}

The RBS spectra of $\mathrm{Cu}_{x} \mathrm{O}$ films are shown in Figures 2 (a) and (b). In agreement with the transmittance behaviour of the films, it is seen that the peak attributed $\mathrm{Cu}$ in the spectra is higher and wider for $\mathrm{Cu}_{x} \mathrm{O}$ thin film samples prepared from DW as solvent than that of sample from ethanol-based precursor solution. This is an indication of relatively thicker precursor solution from DW solvent, which resulted in thicker $\mathrm{CuO}$ films on substrates. The simulation of the spectra using SIMNRA software gave the thickness as 158 $\mathrm{nm}$ and $307 \mathrm{~nm}$ for ethanol and distilled water respectively. The composition of the films obtained from the simulations gave copper and oxygen content to be 50.41 and 49.59 at. \% for alcoholic solvent and 47.81 and 52.19 for DW respectively. Noting that in a stoichiometric $\mathrm{CuO}$, the

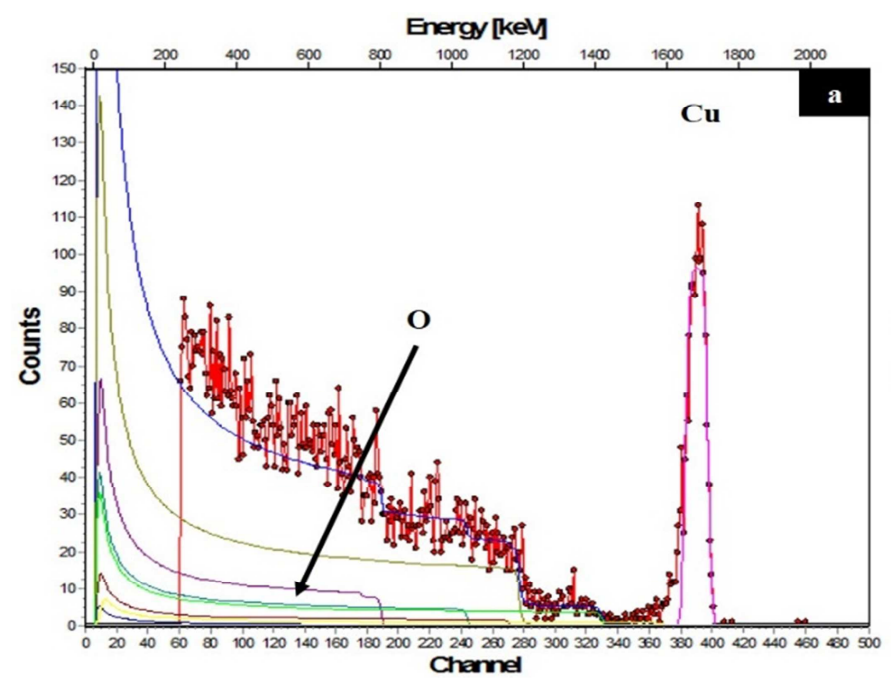

compositions of $\mathrm{Cu}$ and $\mathrm{O}$ are 50.17 at. \% and 49.83 at. \%, then the results obtained for both films compared well with the bulk composition, which indicate that the films are close to being stoichiometric and their compositions can be stated as $\mathrm{Cu}_{1.008} \mathrm{O}_{0.992}$ and $\mathrm{Cu} 0.956 \mathrm{O} 1.044$ for ethanol and DI water solvents respectively (Table 1 ). Moreover, the $\mathrm{Cu} / \mathrm{O}$ ratio in $\mathrm{CuO}$ and $\mathrm{Cu} 2 \mathrm{O}$ should be 1 and 2 respectively. If the films are considered to be $\mathrm{CuO}$ then the RBS results gave the $\mathrm{Cu} / \mathrm{O}$ ratios of 1.02 and 0.91 , which is close to 1 for alcohol and distilled water. It can then be concluded that the films are $\mathrm{CuO}$ and it is therefore plausible to deduce that that there is a deficiency of oxygen with cation compensation in ethanolbased solution, and cation deficiency with oxygen compensation for the aqueous solution samples.

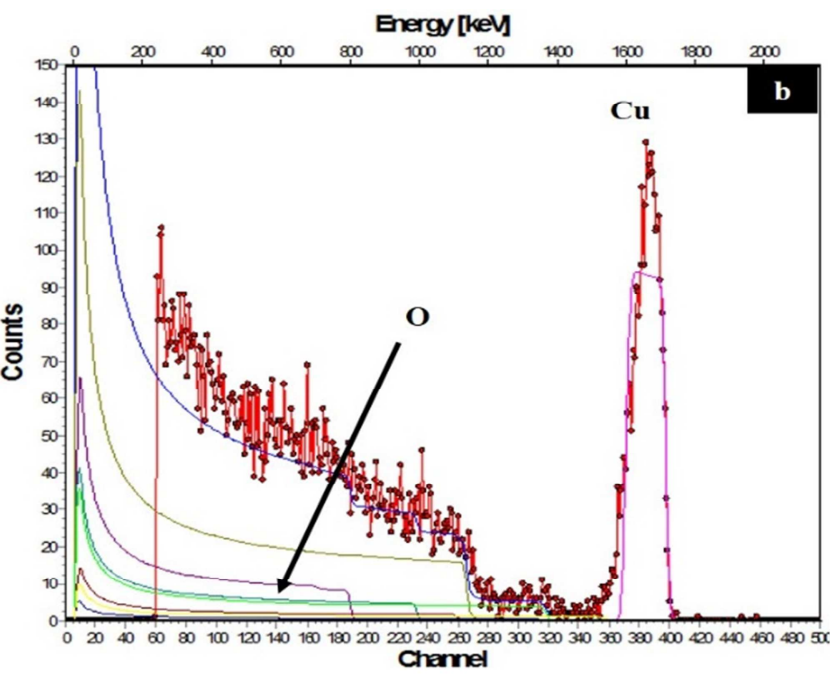

Figure 2. RBS spectra for CuO films deposited with 80 passes using (a) alcohol and (b) distilled water as the precursor solvents. 
Table 1. Elemental composition and thickness values of the spray pyrolyzed $C u_{x} O$ thin films.

\begin{tabular}{|c|c|c|c|c|c|c|}
\hline \multirow[b]{2}{*}{$\mathbf{S} / \mathbf{N}$} & \multirow[b]{2}{*}{ Solvent } & \multirow[b]{2}{*}{ Thickness (nm) } & \multicolumn{2}{|c|}{ Elemental composition (\%) } & \multirow{2}{*}{$\mathrm{Cu} / \mathrm{O}$ ratio } & \multirow{2}{*}{ Stoichiometry } \\
\hline & & & $\mathrm{Cu}$ & $\mathbf{O}$ & & \\
\hline 1 & Ethanol & 158 & 50.41 & 49.59 & 1.02 & $\mathrm{Cu}_{1.008} \mathrm{O}_{0.992}$ \\
\hline 2 & DI water & 307 & 47.81 & 52.19 & 0.92 & $\mathrm{Cu}_{0.956} \mathrm{O}_{1.044}$ \\
\hline
\end{tabular}

\subsection{Optical Characterizations}

\subsubsection{Bandgap Energy}

Assuming the valence band and the conduction bands density of state to be parabolic, Tauc's relation for determining the band gap can be written as equation (1):

$$
(\alpha h v)^{1 / n}=A\left(h v-E_{g}\right)
$$

where $\alpha$ is the absorption coefficient, $E_{g}$ is the band gap of the material, $A$ is a band tailing constant, $h v$ is photon energy and $n$ is a power factor that determines the type of transition which can take values of $1 / 2,3 / 2,2$ and 3 for direct allowed, direct forbidden, indirect allowed and indirect forbidden transition respectively. With the value of thickness obtained from RBS and the transmittance spectra, the absorption coefficient can be calculated from equation 2 ,

$$
\alpha=\frac{1}{t} \operatorname{In} \frac{1}{T}
$$

There are two ways of determining the band gap from Tauc's equation. One way is to plot $\alpha^{2}$ versus $h v$ and if this forms a straight line then it can be inferred that there is a direct band gap, measurable by extrapolating the straight line to $\alpha=0$ axis. On the other hand, if a plot of $\alpha^{1 / 2}$ versus $h v$ forms a straight line, it can again be inferred that there is an indirect band gap, measurable by extrapolating the straight line to the $\alpha$ $=0$ axis (assuming phonon energy $E_{p} \approx 0$ ) [1]. The other way is to plot $(\alpha h v)^{1 / n}$ versus $h v$ in which part of the curve will be linear and the extrapolation of this linear part to intercept the $h v$ axis at $(\alpha h v)^{I / n}$ will give the bang gap. The band gap determination plots are shown in Figures 3(a) and (b). Figure 3 (a) presents the variation of the absorption coefficient " $\alpha$ " with photon energy taking into consideration direct $(n=1 / 2$, inset) and indirect $(n=2)$ transitions. It can be observed that the inset, which is supposed to represent direct transition is not a straight line whereas only the indirect transition produced a straight line which may lead to the conclusion that the films are indirect band gap materials. The band gap energy obtained by making allowance for indirect transition gave 0.61 and 1.07 $\mathrm{eV}$ for alcohol and distilled water respectively. These band gap energy values are too low compared with other study [1]. On the other hand, Figure 3(b) depicts the plot of $(\alpha h v)^{n}$ versus photon energy, assuming direct transition $(n=1 / 2)$ and indirect transition $(n=2)$ as the inset plot. The values of the band gap obtained from the inset plot gave 0.66 and $0.88 \mathrm{eV}$ for the $\mathrm{CuO}$ thin films pyrolyzed from alcohol and DW based precursor solutions respectively; which is even smaller that the values obtained from Figure 3(a). Alternatively, the consideration of direct transition in Figure 3(b) gave band gap values of 2.68 and $2.80 \mathrm{eV}$ for alcohol and DW thin films. The values are summarized in Table 2. The values of $E_{g}$ obtained using $\alpha^{1 / n}$ against $h v$, based on direct transition assumption gave values close to 1.21 to $1.51 \mathrm{eV}$ obtained by other study [2] for $\mathrm{CuO}$ thin films. However, the curves are nonlinear while $(\alpha h v)^{1 / n}$ vs. $h v$ gave values that is slightly higher than the values (2.1 to $2.60 \mathrm{eV}$ ) reported for $\mathrm{Cu}_{2} \mathrm{O}$. The values obtained by considering indirect transition are too low using $\alpha^{1 / n}$ and $(\alpha h v)^{I / n}$ vs. $h v$. This leads to the conclusion that the films may have direct transition with band gap of 1.58 and $1.79 \mathrm{eV}$ and indirect transition with band gap of 2.68 and $2.80 \mathrm{eV}$ for alcohol and aqueous precursor samples. Ogwu et al. [13] reported that many of the growth methods of cuprous oxide result in a combined growth of $\mathrm{Cu}_{2} \mathrm{O}$ and $\mathrm{CuO}$ and the relative ratio of these two oxides in the film will affect device characteristics and the band gap [6]. Therefore, there is probably a small amount of $\mathrm{Cu}_{2} \mathrm{O}$ in the present film samples and this may have contributed to the values of the band gap obtained.

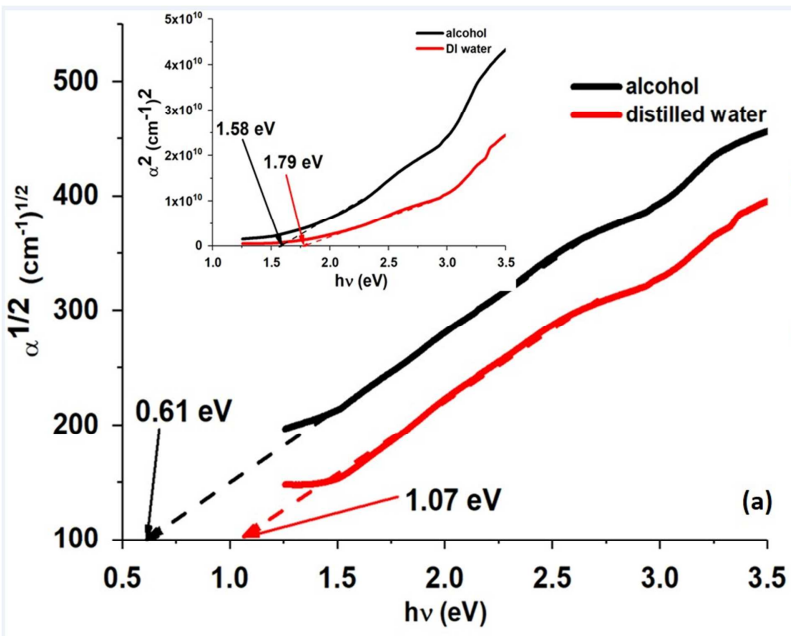

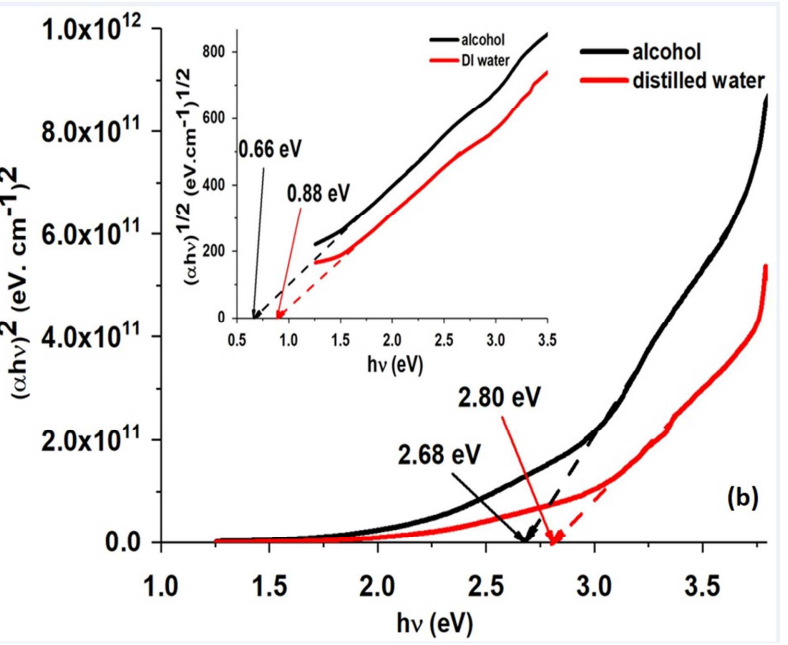

(b)

Figure 3. Variation of (a) $\alpha^{1 / 2}$ and $a^{2}$ (inset) and $(b)(\alpha h v)^{2}$ and $(\alpha h v)^{1 / 2}$ (inset) with energy for band gap determination. 
Table 2. Band gap values obtained assuming direct and indirect transitions.

\begin{tabular}{lllll}
\hline Sample & \multicolumn{2}{l}{ Direct transition $(\mathbf{n}=1 / 2)$} & \multicolumn{2}{l}{ Indirect transition $(\mathbf{n}=\mathbf{2})$} \\
\hline & $\boldsymbol{\alpha}^{1 / \mathbf{n}}$ & $(\boldsymbol{\alpha h v})^{1 / \mathbf{n}}$ & $\boldsymbol{\alpha}^{1 / \mathbf{n}}$ & $(\boldsymbol{\alpha h})^{1 / \mathbf{n}}$ \\
\hline Eg for Alcohol $(\mathrm{eV})$ & 1.58 & 2.68 & 0.61 & 0.66 \\
Eg for Distilled water $(\mathrm{eV})$ & 1.79 & 2.80 & 1.07 & 0.88 \\
\hline
\end{tabular}

\subsubsection{Urbach Tail}

The absorption coefficient depends on the photon energy and localized states appear near the band edge causing band tail formation due to disorder in the films. These band tail states are responsible for the photon absorption [38] in the low energy range with the absorption coefficient given as

$$
\alpha(h v)=\alpha_{o} e^{h v / E_{u}}
$$

Linearization of equation 3 gives

$$
\operatorname{In} \alpha=\operatorname{In} \alpha_{o}+\frac{h v}{E_{u}}
$$

where $\alpha_{o}$ is the pre-exponential factor, $h v$ is the photon energy, and $E_{u}$ is the band tail width, or the disorder energy commonly referred to as Urbach tail. It represents the band gap energy in the absence of tailing and generally as $E_{u}$ increases, the disorder and defect states increase thereby decreasing the band gap [39]. Linearizing equation 3 and plotting $\ln \alpha$ against $h v$ (Equation 4) will produce a straight line and the slope in the lower energy region can be employed to determine $E_{u}$. The result is presented in Figure 4 and the values obtained are 920 and $640 \mathrm{meV}$ for $\mathrm{CuO}$ films from alcohol and distilled water based precursors respectively. The result shows that the films produced using alcohol have more disordered states and this manifest in the reduced band gap compared with that of aqueous samples.

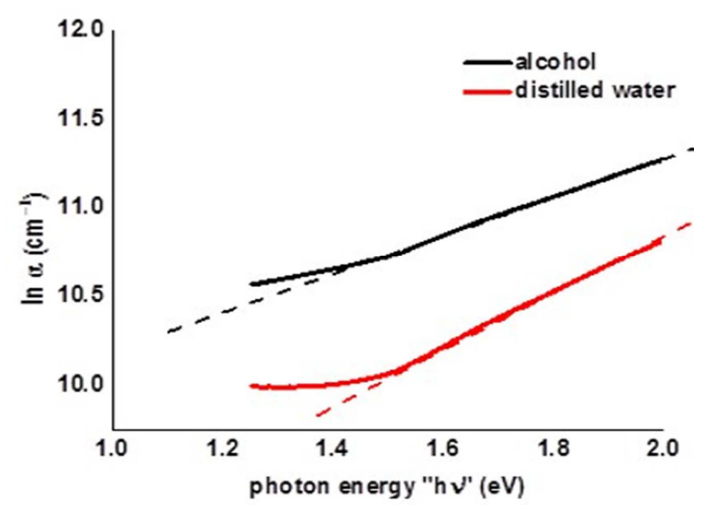

Figure 4. Plot for determining the Urbach energy.

\subsubsection{Refractive Index and the Extinction Coefficient}

The refractive index and the extinction coefficient of the films have been determined from the transmittance measurements for annealed samples prepared with alcohol and aqueous samples. The reflectance " $R$ " in terms of the transmittance can be determined by:

$$
\mathrm{R}=1+\sqrt{\mathrm{T} \cdot \exp (\alpha \cdot \mathrm{t})}
$$

coefficient and " $\mathrm{t}$ " is the thickness acquired from RBS analysis. Based on the values of the reflection as a function of wavelength obtained from equation 3 , the refractive index " $n$ " and the extinction coefficient " $k$ " can also be determined through the following relations,

$$
n=\frac{1+\sqrt{R}}{1-\sqrt{R}} \text { and } k=\frac{\alpha \lambda}{4 \pi}
$$

The variation of percent reflectance, refractive index and the extinction coefficient against wavelength is presented in Figure 5. A strong reflectance in the UV-region which decreases gradually with wavelength for the two solvents with that of aqueous solution being five times greater than that of alcohol. This strong reflectance translates to strong absorption in region I where $\lambda<400 \mathrm{~nm}$. The gradual decrease in reflectance starts from the absorption tail region (region II) near the band edge for $400 \mathrm{~nm}<\lambda<670 \mathrm{~nm}$ and region III representing weak reflectance which is almost invariant for $\lambda>670 \mathrm{~nm}$ in the prepared films. Gadallah et al. [40] observed the same trend on $\mathrm{ZnO}$ thin films prepared by spin coating method, but at different wavelength range. Region I was explained as being due to an electron in the valence band that absorbs certain photon energies and transmits to the conduction band leaving a hole in the valence band, the consequence of which is the formation of excitons. In the absorption tail region representing region II, electron transmits to the shallow states below the conduction band while in region III and there is little or no absorption leading to nearly $100 \%$ transmittance. The refractive index and the extinction coefficient as a function of wavelength are shown in Figure 5(b), they are observed to follow the same trend as the reflectance. Both values are high at lower wavelengths in the region of strong absorption, but with sharp decrease towards longer wavelengths, depicting a normal dispersion behavior. Hassanien et al. [41] attributed this high refractive index to the frequency of the incident photons becoming greater than or equal to the plasma frequency leading to anomalous dispersion of refractive index observed in this region. The figure also shows that the refractive index of the aqueous samples in region $I$ is greater than that of alcohol. This is an indication that the resonance effect between the incoming electro-magnetic radiation and the electron polarization which leads to the coupling of the electrons in the films is stronger in aqueous samples than alcoholic samples. In region III, there is practically no difference in refractive indices of the two samples. The extinction coefficient on the other hand shows a gradual decrease as a function of wavelength, and values smaller than the corresponding refractive index. 

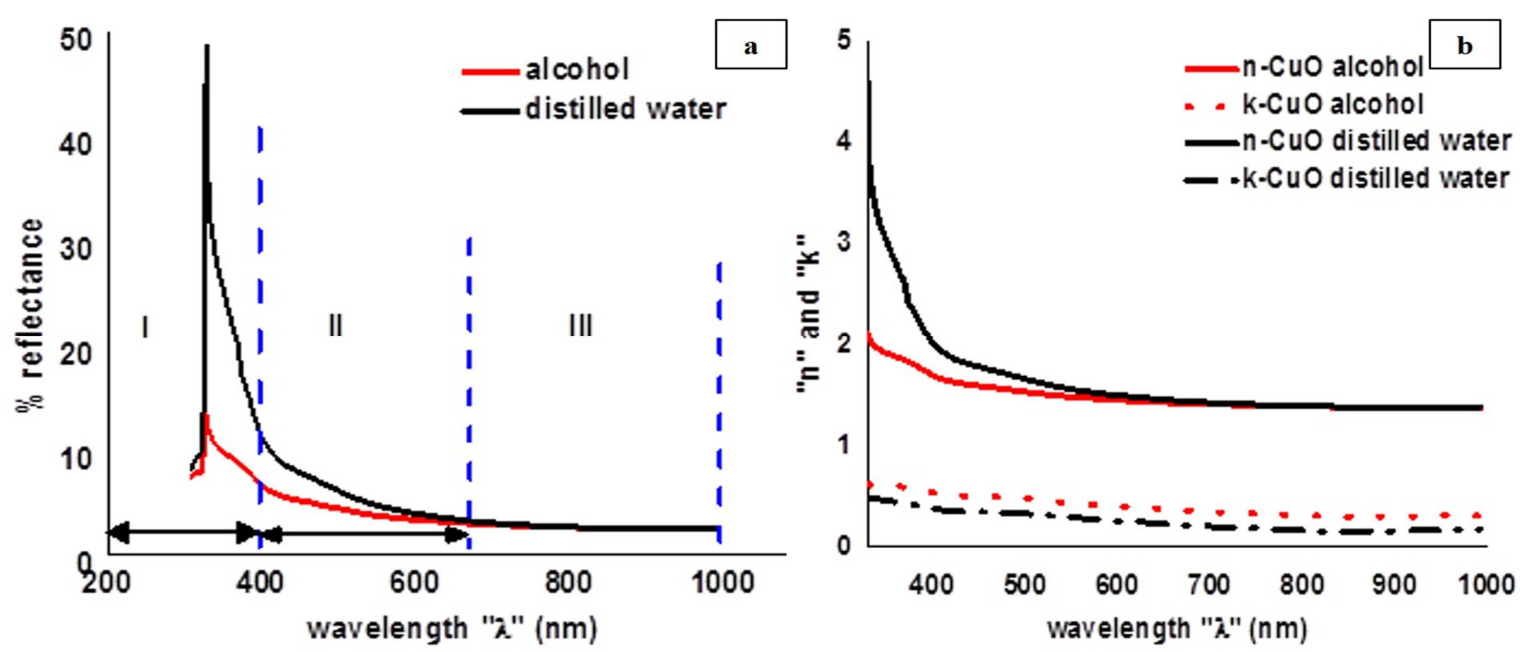

Figure 5. Effect of solvent on (a) percent reflectance (b) extinction coefficient and the refractive index.

\subsubsection{Optical Conductivity}

The optical conductivity $\sigma$ of thin films is strongly dependent on the absorption coefficient $\alpha$, refractive index $n$, speed of light $\mathrm{c}$ and the extinction coefficient $k$ through the following equation,

$$
\sigma=\frac{\alpha n c}{4 \pi k}
$$

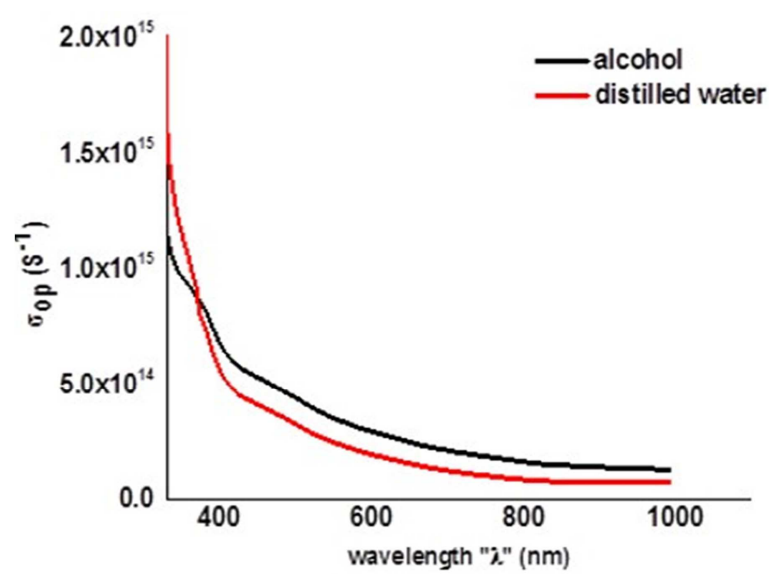

Figure 6. Plot of optical conductivity against wavelength showing high conductivity at high frequency.

Figure 6 illustrates the dependence of the optical conductivity on the incident photon wavelength for both aqueous and alcohol samples. The optical conductivity decreases as the wavelength increases and at high photon energy, the optical conductivity is very high for both precursors. Hassanien [3] attributed this high optical conductivity to the high absorbing nature of thin films in that region and probably due to the excitation of electrons by the energy of the photons.

\subsubsection{Dispersion Parameters}

The refractive index dispersion has been used through the single oscillator model of free carrier absorption to determine the dispersion parameters such as the effective single oscillator and dispersion energy $E_{s o}$ and $E_{d}$ respectively. This model presented in equation 8 gives a physical interpretation of the measured quantities;

$$
\left(n^{2}-1\right)=\frac{E_{d} E_{S o}}{E_{S o}^{2}-(h v)^{2}}
$$

Linearization gives

$$
\left(n^{2}-1\right)^{-1}=\frac{E_{S o}^{2}}{E_{d} E_{S o}}-\frac{(h v)^{2}}{E_{d} E_{S o}}
$$

Equation 9 holds for photon energies well below $E_{s o}$. At energies approaching $E_{s o}$, deviations from equation 9, originating from the proximity of the main band-to-band transitions, are measured. So, the plot of $\left(n^{2}-1\right)^{-1}$ on the y-axis and $(h v)^{2}$ on the $\mathrm{x}$-axis should give a straight line where the intercept on the y-axis gives $E_{s o} / E_{d}$ and the slope equals $1 / E_{d} E_{s o}$. The plot is depicted in Figure 7 where the analyses of the slopes and the intercepts for alcohol and aqueous samples gave the values of $E_{s o}$ and $E_{d}$ tabulated in Table 3. It has been shown [4] that the oscillator energy is often twice the bandgap energy, that is $E_{s o} \approx 2 E_{g}$ and from the values of $E_{s o}$ obtained from Figure $7 \mathrm{a}$, the ratio of $E_{s o} / E_{g}$ obtained are 2.42 and 1.83 for alcohol and aqueous samples respectively. This is probably an indication of better integrity of the films prepared using alcohol. Additionally, the values of $E_{s o}$ and $E_{d}$ can be employed to determine the zero-frequency dielectric constant $\varepsilon_{o}$ and zero-frequency refractive index $n_{o}$ by rewriting equation 8 putting $h v=0$ giving:

$$
\varepsilon_{o}=n_{o}^{2}=1+\frac{E_{d}}{E_{s o}}
$$

The calculated values are again presented in Table 1 which shows the values for both samples to be of the same order of magnitude with alcoholic samples having a higher value. The average oscillator strength " $S_{o}$ " and the average oscillator wavelength " $\lambda_{0}$ " in the model can also be determined by employing the long wavelength approximation of the singleterm Sellmier relation [5] given, 


$$
n^{2}-1=\frac{S_{o} \lambda_{o}^{2}}{\left[1-\left(\frac{\lambda_{o}}{\lambda}\right)^{2}\right]}
$$

Which can be rewritten as

$$
\left(n^{2}-1\right)^{-1}=\frac{1}{S_{o} \lambda_{o}^{2}}-\frac{1}{S_{o} \lambda^{2}}
$$

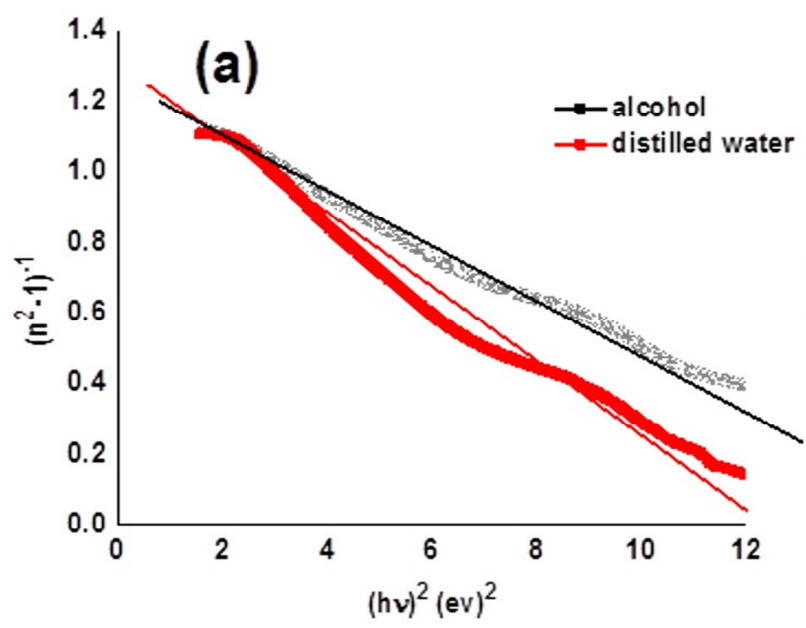

The plot of $\left(n^{2}-1\right)^{-1}$ on the $\mathrm{y}$-axis against $1 / \lambda^{2}$ on the $\mathrm{x}$ axis gives a straight line with $1 / S_{o} \lambda_{o}^{2}$ as the intercept on the $\mathrm{y}$-axis and $1 / S_{o}$ as the slope. This is shown in Figure $7(\mathrm{~b})$ and the values determined are also shown in Table 2.

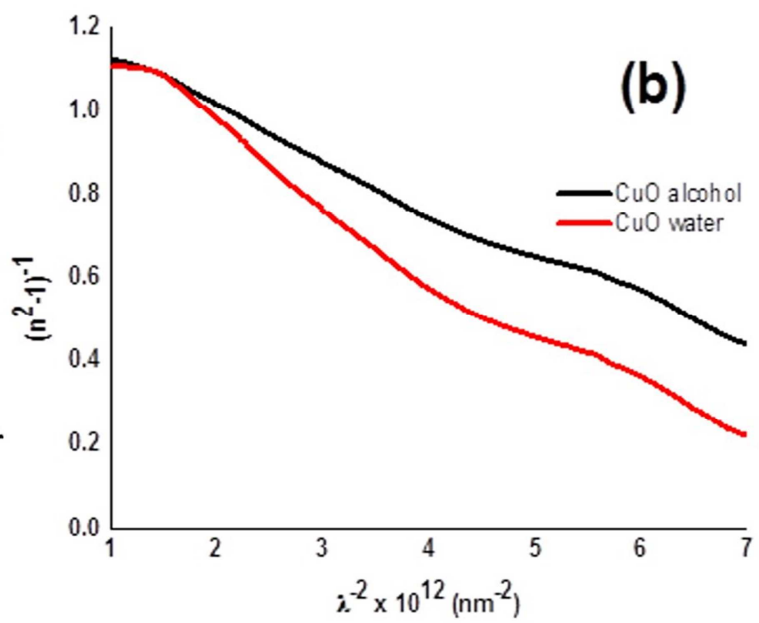

Figure 7. Variation of refractive index factor $\left(n^{2}-1\right)^{-1}$ against $(a)(h v)^{2}$ for the determination of $E_{d}$ and $E_{s o}$ and (b) $1 / \lambda^{2}$ for the determination $S_{o}$ and $\lambda_{0}$.

\subsubsection{Density of State}

The refractive index dispersion can be used to obtain the ratio of the density of state to the effective mass $\mathrm{N} / \mathrm{m}^{*}$ and the high frequency dielectric constant $\varepsilon_{\infty}$ through the following equation,

$$
n^{2}=\varepsilon_{\infty}-\frac{1}{4 \pi^{2} \varepsilon_{o}}\left(\frac{e^{2}}{c^{2}}\right)\left(\frac{N_{c}}{m^{*}}\right) \lambda^{2}
$$

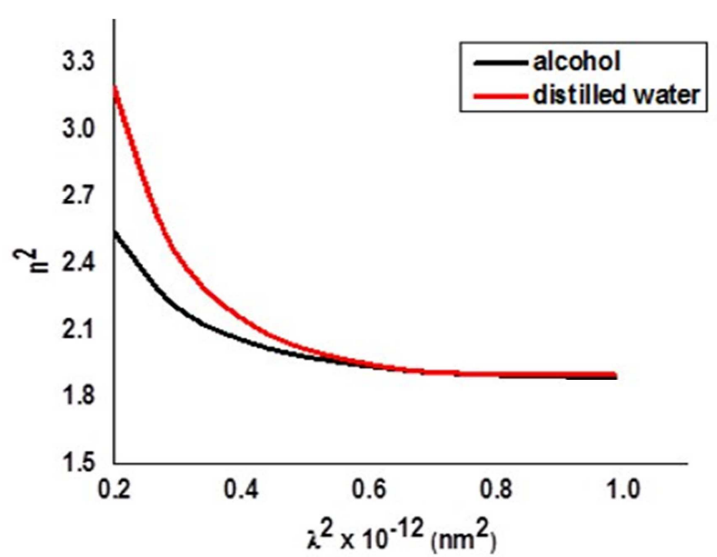

Figure 8. Variation of $n^{2}$ against $\lambda^{2}$ for the determination of $N_{d} d m *$ and $\varepsilon_{\infty}$.

where $e$ is the electronic charge, $N_{c}$ is the density of state or charge carrier density, $m^{*}$ is the effective mass of the carrier and $\varepsilon_{\infty}$ is the high frequency dielectric constant. Plotting $n^{2}$ on the $y$-axis and $\lambda^{2}$ on the $\mathrm{x}$-axis will produce a straight line in the long wavelength region as shown in Figure 8. The extrapolation of the linear part of this curve to $\lambda^{2}=0$ gives the high frequency dielectric constant while the slope $\frac{1}{4 \pi^{2} \varepsilon_{o}}\left(\frac{e^{2}}{c^{2}}\right)\left(\frac{N_{c}}{m^{*}}\right)$ gives the $N_{C} / m *$ ratio. The values obtained are again presented in Table 3. It is observable from the plot that values obtained are relatively close since the values at long wavelength almost coincide.

\subsubsection{Dielectric Constants}

The refractive index " $n$ " and the extinction coefficient " $k$ " are important parameters in determining the real and the imaginary parts of the dielectric constants $\varepsilon_{i}$ and $\varepsilon_{r}$ as well as the loss tangent or the dissipation factor " $\delta$ " through the following equations,

$$
\begin{gathered}
\varepsilon_{r}=n^{2}-k^{2} \\
\varepsilon_{i}=2 n k \\
\tan \delta=\varepsilon_{i} / \varepsilon_{r}
\end{gathered}
$$

Figure 9(a) shows the real and the imaginary parts of the complex dielectric constant against the wavelength for the samples prepared using alcohol and aqueous solution. It is obvious from the plot that the real part of the dielectric constant $\varepsilon_{r}$ is higher than the imaginary parts $\varepsilon_{i}$ in both solvents. This can be explained using equations 14 and 15 where $\varepsilon_{r}$ depends largely on " $n$ " (since $n>k$ ) and $\varepsilon_{i}$ depends largely on " $k$ " which is smaller than " $n$ ". It can also be observed from Figure 9(a) that the real part of the dielectric constant for aqueous samples is higher than that of alcohol while it is the reverse for the imaginary parts. In addition, the difference between $\varepsilon_{r}$ and $\varepsilon_{i}$ is larger in aqueous samples than alcohol samples. This may probably be because of the solvents on the chemistry of the films and an indication that electromagnetic waves will travel faster in alcohol samples than aqueous samples because of the reduced dielectric constants. This also means that the interaction of 
electromagnetic waves with free electrons is stronger in aqueous samples than alcohol samples since $\varepsilon_{r}$ is responsible for reducing the propagation speed of the electromagnetic waves through the material $[42,43]$. Figure $9(b)$ is showing the variation of the loss tangent with wavelength while the inset is showing the same variation with photon energy. Aqueous samples show reduced dielectric loss tangent with respect to alcohol samples. Moreover, aqueous samples show

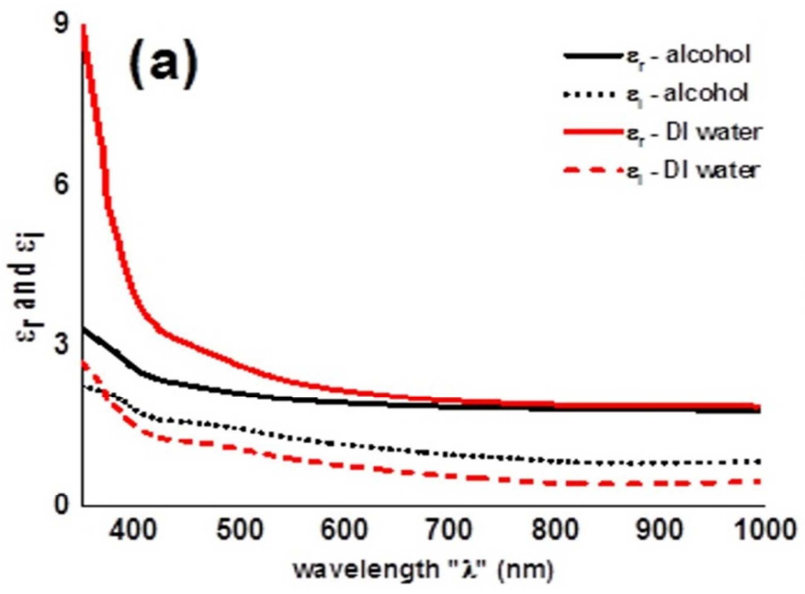

one broad dielectric loss peak centered at $481 \mathrm{~nm}(2.66 \mathrm{eV})$ while alcohol samples manifest three dielectric loss peaks at $325 \mathrm{~nm}(3.8 \mathrm{eV}), 381 \mathrm{~nm}(3.27 \mathrm{eV})$ and $474 \mathrm{~nm}(2.63 \mathrm{eV})$ with gradual decrease towards longer wavelength and becoming constant at $\lambda>750 \mathrm{~nm}$. The observed peaks are indications of different dielectric relaxation mechanisms in the two films.

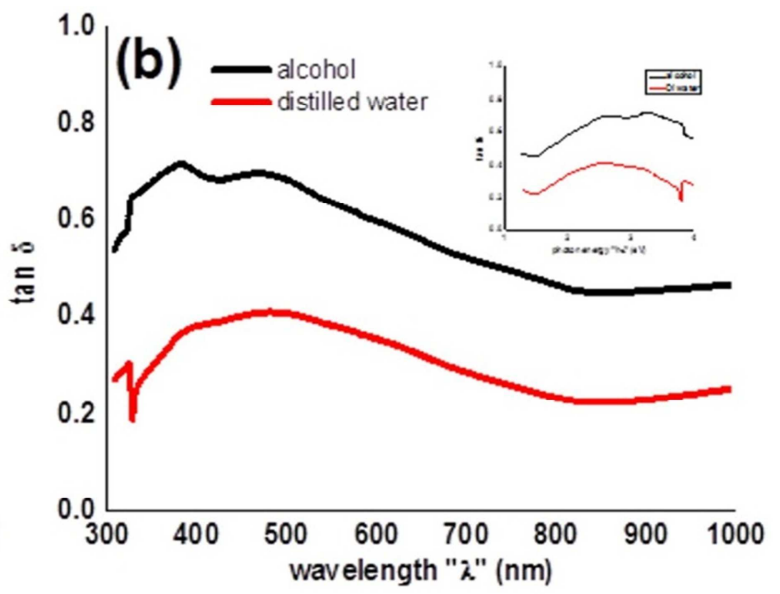

Figure 9. The variation of (a) the dielectric constant and (b) the loss tangent as a function of incident wavelength.

\subsubsection{Relaxation Time and Optical Mobility}

The imaginary part of the dielectric constant $\left(\varepsilon_{r}\right)$ relation with incident photon wavelength can be analyzed to determine the relaxation time " $\tau$ ", optical mobility " $\mu_{\text {opt }}$ " as well as the optical resistivity " $\rho_{\text {opt }}$ " through (17),

$$
\varepsilon_{r}=\frac{1}{4 \pi^{3} \varepsilon_{0}}\left(\frac{e^{2}}{c^{3}}\right) \cdot\left(\frac{N_{c}}{m^{*}}\right) \cdot\left(\frac{1}{\tau}\right) \lambda^{3}
$$

The linear part of the plot of $\varepsilon_{r}$ against $\lambda^{3}$ shown in Figure 10 gives the slope as $\frac{1}{4 \pi^{3} \varepsilon_{0}}\left(\frac{e^{2}}{c^{3}}\right) \cdot\left(\frac{N_{c}}{m^{*}}\right) \cdot\left(\frac{1}{\tau}\right)$ and from $\mathrm{Nc} / \mathrm{m}^{*}$ calculated from equation 13 and taking $\mathrm{m}^{*}=0.44 \mathrm{~m}_{\mathrm{o}}[3]$, the relaxation time $\tau$ can be determined. From the determination of $\tau$, the optical mobility as well as the optical resistivity of the films can be calculated using,

$$
\begin{gathered}
\mu_{o p}=\frac{e \tau}{m^{*}} \\
\rho_{o p}=\frac{1}{e \mu_{o p} N_{c}}
\end{gathered}
$$

From the calculated values listed in Table 3 , it can be observed that the relaxation time, the optical mobility, the charge carrier density and the optical resistivity values of the alcohol samples are respectively $400 \%, 400 \%, 10 \%$ and $21 \%$ greater than the values obtained for the aqueous samples. This is an indication of better performance of alcohol as a solvent in $\mathrm{Cu}_{\mathrm{x}} \mathrm{O}$ film formation using spray pyrolysis technique.

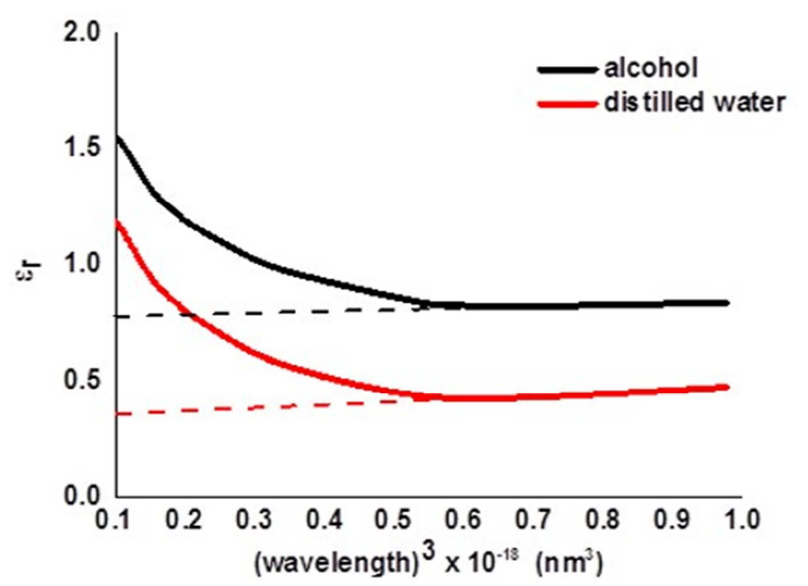

Figure 10. Variation of $\varepsilon_{r}$ versus $\lambda^{3}$ for the determination of relaxation time.

Table 3. Optoelectronic parameters of the deposited films.

\begin{tabular}{llll}
\hline Parameter & Symbol & Alcohol & Distilled water \\
\hline Thickness (nm) & $\mathrm{t}$ & 158 & 307 \\
$\mathrm{Cu}$ content (at. \%) & & 50.41 & 47.81 \\
$\mathrm{O}_{2}$ content (at. \%) & & 49.59 & 52.19 \\
Stoichiometry & & $\mathrm{Cu}_{1.008} \mathrm{O}_{0.992}$ & $\mathrm{Cu}_{0.956} \mathrm{O}_{1.044}$ \\
Average oscillator strength $\left(\mathrm{m}^{-2}\right)$ & $\mathrm{S}_{\mathrm{o}}$ & $7.47 \times 10^{12}$ & $5.1 \times 10^{12}$ \\
Average oscillator wavelength $(\mathrm{m})$ & $\lambda_{\mathrm{o}}$ & $3.33 \times 10^{-7}$ & $3.78 \times 10^{-7}$ \\
Dispersion parameter $\left(\mathrm{eV} . \mathrm{m}^{2}\right)$ & $\mathrm{E}_{\mathrm{o}} / \mathrm{S}_{\mathrm{o}}$ & $5.2 \times 10^{-13}$ & $6.4 \times 10^{-13}$ \\
\hline
\end{tabular}




\begin{tabular}{llll}
\hline Parameter & Symbol & Alcohol & Distilled water \\
\hline Single oscillator strength $(\mathrm{eV})$ & $\mathrm{E}_{\mathrm{so}}$ & 3.82 & 3.28 \\
Dispersion energy $(\mathrm{eV})$ & $\mathrm{E}_{\mathrm{d}}$ & 2.97 & 2.41 \\
High frequency dielectric constant & $\varepsilon_{\propto}$ & 2.04 & 2.03 \\
Zero frequency dielectric constant & $\varepsilon_{\mathrm{o}}$ & 1.78 & 1.33 \\
Zero frequency refractive index & $\mathrm{n}_{\mathrm{o}}$ & $2.01 \times 10^{56}$ & 1.73 \\
Density of state effective mass ratio $\left(\mathrm{m}^{-3} \cdot \mathrm{kg}^{-1}\right)$ & $\mathrm{N}_{\mathrm{c}} / \mathrm{m}^{*}$ & $8.05 \times 10^{25}$ & 1.31 \\
Optical charge carrier density $(\mathrm{m}-3)$ & $\mathrm{N}_{\mathrm{c}}$ & 1.58 & $1.82 \times 10^{56}$ \\
Band gap (eV) & $\mathrm{E}_{\mathrm{g}}$ & 920 & $7.29 \times 10^{25}$ \\
Urbach energy (meV) & $\mathrm{E}_{\mathrm{u}}$ & $6.02 \times 10^{-15}$ & 1.79 \\
Relaxation time $(\mathrm{s})$ & $\tau$ & $2.41 \times 10^{-3}$ & 640 \\
Optical mobility & $\mu_{\mathrm{op}}$ & $3.22 \times 10^{-5}$ \\
Optical resistivity & $\rho_{\mathrm{op}}$ & & $1.43 \times 10^{-15}$ \\
\hline
\end{tabular}

\section{Conclusion}

Well adherent and transparent dark brown copper oxide thin films have been deposited on glass using alcohol and distilled water as solvents. Rutherford backscattering analysis revealed the aqueous films to be thicker than that of alcohol and the composition of the two films to be $\mathrm{CuO}$ with oxygen deficiency and cation compensation for alcohol and cation deficiency with oxygen compensation for the aqueous samples. The band gap calculated using direct transition for aqueous samples $(1.79 \mathrm{eV})$ are higher than that of alcohol $(1.58 \mathrm{eV})$ and for indirect transition, the values obtained are 2.60 and $2.86 \mathrm{eV}$ for alcohol and aqueous samples respectively. The refractive index, which showed normal dispersion behavior have been used through single oscillator Sellmier model to calculate some optical and optoelectronic parameters. The loss tangent of the aqueous samples shows one broad dielectric loss peak while alcohol samples manifest three dielectric loss peaks. The observed peaks are probably indications of different dielectric relaxation mechanisms occurring in the two films. The optical conductivity manifests a high value at high energy of the incident photon indicating the high absorbing nature of the films and electron excitation. The values of the calculated optical mobility and the relaxation time of the alcohol samples are $400 \%$ higher than that of aqueous samples while the charge carrier density and the optical resistivity values of the alcohol samples are $10 \%$ and $21 \%$ greater than the values obtained for the aqueous samples. The results demonstrated that alcohol precursor leads to films of better properties which can be employed as solar cell absorber or optical windows.

\section{Acknowledgements}

The support of Center for Energy Research and Development, Obafemi Awolowo University, Ile-Ife, Nigeria is gratefully acknowledged.

\section{References}

[1] M. R. Johan, M. S. Mohd Suan, N. L. Hawari and H. A. Ching, Int. J. of Electrochem. Soc., vol. 6, pp. 6094-6104, 2011.

[2] J. X. Wang, X. W. Sun, Y. Yang, K. K. Akyaw, X. Y. Huang, J. Z. Yin, J. Wei and H. V. Demir, "Free-Standing $\mathrm{ZnO}-\mathrm{CuO}$ Composite Nanowire Array Films and their Gas Sensing Properties," Nanotechnology, vol. 22, p. 325704, 2011.

[3] Z. H. Ibupoto, K. Khun, V. Beni, X. Liu and M. Willander, "Synthesis of Novel $\mathrm{CuO}$ Nanosheets and Their NonEnzymatic Glucose Sensing Applications," Sensors, vol. 13, pp. 7926-7938, 2013.

[4] R. Z. Zhan, J. Chen, S. Z. Deng and N. S. Xu, "Fabrication of gated $\mathrm{CuO}$ nanowire field emitter arrays for application in field emission display," J. Vac. Sci. Technol., vol. 28, p. 558, 2010.

[5] J. Dattarya, P. Shailesh, C. Manik, G. Prasad, R. Sanjay, R. Bharat, S. Shashwati and P. Vikas, "Nanocrystalline $\mathrm{CuO}$ Thin Films for H2S Monitoring: Microstructural and Optoelectronic Characterization," J. of Sensor Technology, vol. 1, pp. 36-46, 2011.

[6] J.-W. Han and M. Meyyappin, "Copper Oxide Resistive Switching Memory for e-textile," AIP Advances, vol. 1, 2011.

[7] P. Raksa, S. Nilphai, A. Gardchareon and S. Choopun, "Copper oxide thin film and nanowire as a barrier in $\mathrm{ZnO}$ dyesensitized solar cells," Thin Solid Films, vol. 517, no. 17, pp. 4741-4744, 2009.

[8] H. Y. Bae and G. M. Choi, "Electrical and reducing gas sensing properties of $\mathrm{ZnO}$ and $\mathrm{ZnO}-\mathrm{CuO}$ thin films fabricated by spin coating method," Sensors and Actuators B: Chemical, vol. 55 , no. 1 , pp. 47-54, 1999.

[9] Kosyachenko, L A, Solar Cells - New Aspects and Solutions, In Tech Publisher, 2011.

[10] D. P. Singh, J. Singh, P. R. Mishra, R. S. Tiwari and O. N. Srivastava, "Synthesis, Characterisation and Application of Semiconducting Oxide (Cu2O and $\mathrm{ZnO})$ nanostructures," Bulletin of Materials Science, vol. 31, no. 3, pp. 319-325, 2008.

[11] W. Siripala, L. D. R. D. Perera, K. T. L. De Silva, J. K. D. S. Jayanetti and I. M. Dharmadasa, "Study of annealing Effects of Cuprous Oxide Grown by Electrodeposition Technique," Solar Energy Materials and Solar Cells, vol. 44, no. 3, pp. 251-260, 1996. 
[12] Y. Tang, Z. Chen, Z. Jia, L. Zhang and J. Li, "Electrodeposition and Characterisation of Nanocrystalline Films of Cuprous Oxide Thin Films on $\mathrm{TiO}_{2}$," Materials Letters, vol. 59, no. 4, pp. 434-438, 2005.

[13] A. A. Ogwu, T. H. Darma and E. Bouquerel, "Electricak Resistivity of Copper Oxide Thin Films Prepared by Reactive Magnetron Sputtering," Journal of Achievements in Materials and Manufacturing Engineering, 24(1), (2007),, vol. 24, no. 1, pp. 172-177, 2007.

[14] G. Papadimitropoulos, N. Vourdas, V. E. Vamvakas and D. Dazavoglou, "Optical and Structural Properties of Copper Oxide Thin Films Grown by Oxidation of Metal Layers," Thin Solid Films, vol. 515, pp. 2428-2432, 2006.

[15] G. Lai, H. Lan, S. Lin, Y. Qu and F. Lai, "Optical Properties of the Oxidation of $\mathrm{Cu}$ thin Films Prepared by Thermal Evaporation," Surface Review Letters, vol. 20, no. 1, p. 135001, 2013.

[16] O. Fasakin, M. A. Eleruja, O. Akinwunmi, B. Olofinjana, E. Ajenifuja and E. O. B. Ajayi, "Synthesis and Characterization of Metal Organic Chemical Vapour Deposited Copper Titanium Oxide $(\mathrm{Cu}-\mathrm{Ti}-\mathrm{O})$ Thin Films from Single Solid Source Precursor," Journal of Modern Physics, vol. 4, no. 12C pp. 1-6, 2013.

[17] N. Serin, T. Serin, S. Horzum and Y. Celik, "Annealing effects on the properties of copper oxide thin films prepared by Chemical Deposition.," Semiconductor Science and Technology.

[18] D. P. Dubal, G. S. Gund, R. Holze, H. S. Jadhav, C. D. Lokhande and C.-J. Park, "Surfactant-Assisted Morphological Tuning of Hierarchical CuO Thin Films for Electrochemical Supercapacitors," Dalton Transaction, vol. 42, pp. 6459-6467, 2013.

[19] V. F. Drobny and D. L. Pulfrey, "Properties of ReactivelySputtered Copper Oxide Thin Films," Thin Solid Films, vol. 61, no. 1, pp. 89-98, 1979.

[20] L. Nkhail, M. Elyaagoubi, A. Elmansouri, A. El Kissani, A. El Khalfi, A. El Fathi, M. Ait Ali and A. Outzourhit, "Structural, Optical, and Electrical Characteristics of Zinc Oxide and Copper Oxide Films and Their Heterojunctions," Spectroscopic Letters, vol. 48, no. 7, pp. 536-541, 2015.

[21] E. Ajenifuja, A. Y. Fasasi and G. A. Osinkolu, "SputteringPressure Dependent Optical and Microstructural Properties Variations in DC Reactive Magnetron Sputtered Titanium Nitride Thin Films," Transactions of the Indian Ceramic Society, vol. 71, no. 4, pp. 181-188, 2012.

[22] E. Ajenifuja, A. P. I. Popoola and O. Popoola, "Thickness Dependent Chemical and Microstructural Properties of DC Reactive Magnetron Sputtered Titanium Nitride Thin Films on Low Carbon Steel Cross-section," Journal of Material Research and Technology, 2018.

[23] E. Ajenifuja, A. Y. Fasasi and G. A. Osinkolu, "SputteringPressure Dependent Optical and Microstructural Properties Variations in DC Reactive Magnetron Sputtered Titanium Nitride Thin Films," Transactions of the Indian Ceramic Society, vol. 71, no. 4, pp. 181-188, 2012.

[24] V. Dhanasekaran and T. Mahalingam, "Electrochemical Deposition and Characterisation of Cupric Oxide Thin Films," J. Nanosci. Nanotechnol., vol. 13, no. 1, pp. 250-259, 2013.

[25] H. Kidowaki, T. Oku and A. Akiyama, "Fabrication and Evaluation of $\mathrm{CuO} / \mathrm{ZnO}$ Heterostructures for Photoelectric Conversion," IJRAS, vol. 13, no. 1, pp. 67-72, 2012.
[26] V. Dahiya, A. Kumar, G. Kaur and A. Mitra, "Investigation of variation of energy of laser beam on structural, electrical and optical properties of pulsed laser deposited $\mathrm{CuO}$ thin films," in Conference 58, DAE Solid State Symposium, 2013.

[27] N. S. Saadat and F. E. Ghodsi, "Effect of pH on the Properties of Nanocrystalline $\mathrm{CuO}$ Thin Films Deposited by Sol-Gel Process," Russ. J. Phys. Chem., vol. 87, no. 1, pp. 84-87, 2013.

[28] S. C. Ray, "Preparation of copper oxide thin film by the solgel-like dip technique and study of their structural and optical properties," Solar Energy Materials and Solar Cells, vol. 68, no. 3-4, pp. 307-312, 2001.

[29] A. Y. Oral, E. Mensur, M. H. Aslan and E. Basaran, "The preparation of Copper (II) oxide thin films and the study of their microstructures and optical properties," Materials Chemistry and Physics, vol. 83, no. 1, pp. 140-144, 2004.

[30] M. Ristov, G. I. Sinadnovski and V. N. Singh, "Resistive Switching in Copper Oxide Nanorods: A Bottom Up Approach Applicable for Enhanced Scalability," J. Nanosci. Nanotech., vol. 11, no. 10, pp. 8538-8542, 2011.

[31] H. Samir, A. Riyam and I. Jadaan, "Study of the Optical Properties of Copper Oxide Thin Film Deposited by Cold Spray," AL-Qadisiya J. for Engineering Sciences, vol. 6, no. 4, p. 439-454, 2013.

[32] M. Engin, F. Atay, S. Kose, V. Bilgin and I. Akyuz, "Growth and Characterization of Zn-Incorporated Copper Oxide Films," J. Elec. Mater., vol. 38, no. 6, pp. 787-796, 2009.

[33] Y. S. Chaudhary, A. Agrawal, R. Shrivastas, V. R. Satsangi and S. Dassi, "A study on the Photoelectrochemical Poperties of Copper Oxide Thin Films," Int. J. of Hydrogen Energy, vol. 29, no. 2, pp. 131-134, 2004.

[34] J. Morales, L. Sanchez, F. Martin, J. R. Ramos-Barrado and M. Sanchez, "Use of Low-Temperature Nanostructured $\mathrm{CuO}$ Thin Films Deposited by Spray-Pyrolysis in Lithium Cells," Thin Solid Films, vol. 474, no. 1-2, pp. 133-140, 2005.

[35] A. E. Adeoye, E. Ajenifuja, B. A. Taleatu and Y. A. Fasasi, "Rutherford Backscattering Spectrometry Analysis and Structural Properties of Znxb1- $x$ Thin Films Deposited by Chemical Spray Pyrolysis," Journal of Materials, vol. 2015, p. 8, 2015.

[36] A. E. Adeoye, E. Ajenifuja, B. A. Taleatu, E. D. Ogunmola, E. Omotoso, O. Adeyemi and O. G. Babatunde, "Surface microstructure, optical and electrical properties of spray pyrolyzed $\mathrm{PbS}$ and $\mathrm{Zn}-\mathrm{PbS}$ thin films for optoelectronic applications," Materials Science-Poland, vol. 35, no. 3, pp. 576-582, 2017.

[37] T. Mahalingam, V. Dhanasekaran, G. Ravi, S. Lee, J. P. Chu and H.-J. Lim, " Effect of Deposition Potential on the Physical Properties of Electrodeposited $\mathrm{CuO}$ Thin Films," J. Optoelect, and Adv. Materials, vol. 12, no. 6, pp. 1327-1332, 2010.

[38] M. Lamri Zeggar, F. Bourfaa, A. Adjimi, F. Boutbakh, M. S. Aida and N. Attaf, "CuO Thin Films Deposited by Spray Pyrolysis: Influence of Precursor Solution Properties," Int. J. of Mathematical, Computational, Physical, Electrical and Computer Engineering, vol. 9, no. 10, pp. 618-621, 2015.

[39] A. S. Hassanien and A. A. Akl, "Effect of Se Addition on Optical and Electrical Properties of Chalcogenide CdSSe Thin Films," Superlattices and Microstructures, vol. 89, pp. 153169, 2016. 
[40] A. S. Gadallah and M. M. El-Nahass, "Structural, Optical Constants and Photoluminescence of $\mathrm{ZnO}$ Thin Films Grown by Sol-Gel Spin Coating," Advances in Condensed Matter Physics, vol. 2013, p. 11, 2013.

[41] A. S. Hassanien and A. A. Akl, " Influence of Composition on Optical and Dispersion Parameters of Thermally Evaporated Non-Crystalline Cd50S50-xSex Thin Films," Journal of Alloys and Compounds, vol. 648, pp. 280-290, 2015.

[42] A. S. Hassanien, "Studies on Dielectric Properties, Optelectrical Parameters and Electronic Polarizability of Thermally Evaporated Amorphous Cd50S50-xSex," Journal of Alloys and Compounds, vol. 671, pp. 566-578, 2016.
[43] A. Fasasi, B. D. Ngom, J. B. Kana-Kana, R. Bucher, M. Maaza, C. Theron and U. Buttner, "Synthesis and Characterisation of Gd-doped BaTiO3 Thin Films Prepared by Laser Ablation for Optoelectronic Applications," J. Phys. \& Chem. Solids, vol. 70, pp. 1322-1329, 2009.

[44] G. A. Artioli, A. Manchini, V. R. Barbieri, M. C. Quattrini, E. Quartarone, M. C. Mozzati, G. Drera, L. Sangaletti, V. Gombac, P. Fomasiero and L. Malavasi, "Correlation between Deposition Parameters and Hydrogen Production in $\mathrm{CuO}$ Nanostructured Thin Films," Langmuir, vol. 32, no. 6, pp. 1510-1520, 2016. 